\title{
Relevant Analysis of China's Commercial Housing Price Changes and Resident Income Based on Data Processing
}

\author{
Li Ming
}

Jilin Business Technology and college, Zhangchun130061, China

120857715@qq.com

KeyWords: Commercial Housing Price; Per Capita Income; Alterable Relation

\begin{abstract}
The commercial residential industry has high added value and comprehensive economic benefit so the commercial residential industry is naturally a hot-spot issue. The core issue of the commercial housing is the price. This thesis conducts the descriptive statistic analysis of residential real estate prices, urban resident income and other relevant data in China's 30 provinces (excluding Tibet) from 1998 to 2006. The change trend and the difference feature of both the residential real estate price and the urban resident income in those regions are revealed, which is expected to make a contribution to the macro-control in China's real estate.

In recent years, the real estate market in China is growing rapidly. On the one hand, it plays a vital role in both promoting the national economic growth and improving the living standards of urban residents. On the other hand, some problems in the development of China's current real estate market have been fully exposed, such as the overheated investment, the unbalance in supply and demand, insufficient financing channels, soaring property prices and so on. In particular, the rapid growth in the housing price has brought challenges to the sound development in both China's real estate market and the whole national economy and it has also become a hot-spot and difficult issue in the current academia. Such relevant research as whether the rapid growth of China's housing prices has become disjointed with resident income seriously or not and what the rules of the changes in income and housing prices in China's different regions are is realistically significant for guiding the micro-control in China's real estate.
\end{abstract}

\section{Index Selection and Disposal of Comparability}

The samples selected in this thesis are composed of the fluctuating residential real estate prices in China's 30 provinces (excluding Tibet) from 1998 to 2006, urban resident income and other relevant panel data that are from various years of China Statistical Yearbook. The data of the real estate prices adopts the real estate prices in urban areas. The income indexes adopt the annual per capita disposable income of urban residents. In order to remove the impacts of the price and make indexes of various types had comparability in time series, the disposal of comparability has been conducted in indexes of different types in the thesis and their present value has been turned into the value of the constant price, namely, on the basis of the constant price in 1998, the concrete calculation method is that the housing price is deflated by the housing sales price index and the disposable income is deflated by the consumer price index of urban residents.

\section{Analysis of Commercial Housing Price Variance among Provinces}

According to the average housing prices and their growth rates in provinces from 1998 to 2006, thirty provinces, cities and autonomous regions across the country can be divided into three types in accordance with the mean and the growth rate of their average housing prices. It's found that the provinces, cities and autonomous regions of the three types also have common in geographic areas so they can be divided into such three regions as the eastern region, the central region and the western region on the basis of their geographic areas.

For the regional division of the average housing price in China, Figure 1 compares the changes in the average housing prices in the central, western and eastern regions from 1998 to 2006. It's found that the average housing price in the east is prominently higher than those in the western and 
central regions and the trend of its average housing prices is on the rise. In particular, the rising trend of the average housing prices is obvious after 2004. The changes in the average housing prices in eastern and western regions are comparatively similar. However, the average prices in the central region are rising slowly while for the western region, a small decline also appears in its slightly rising process. Besides, the average housing prices in the eastern region surpass those in the western region after 2004.

\section{Analysis of the Differences in the Income Change among Regions}

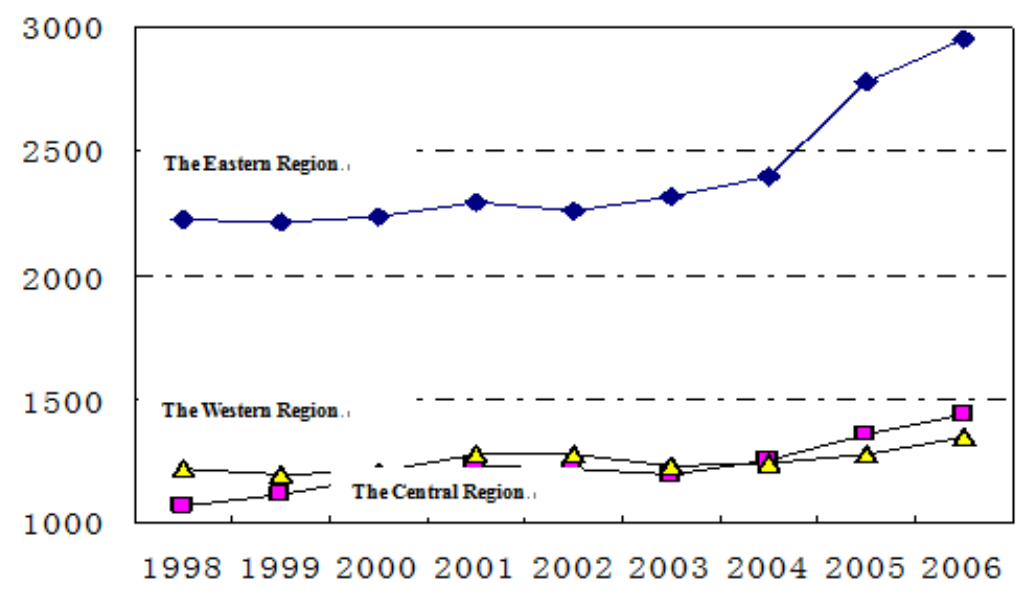

Figure 1: Changes in the housing prices in the central, eastern and western regions

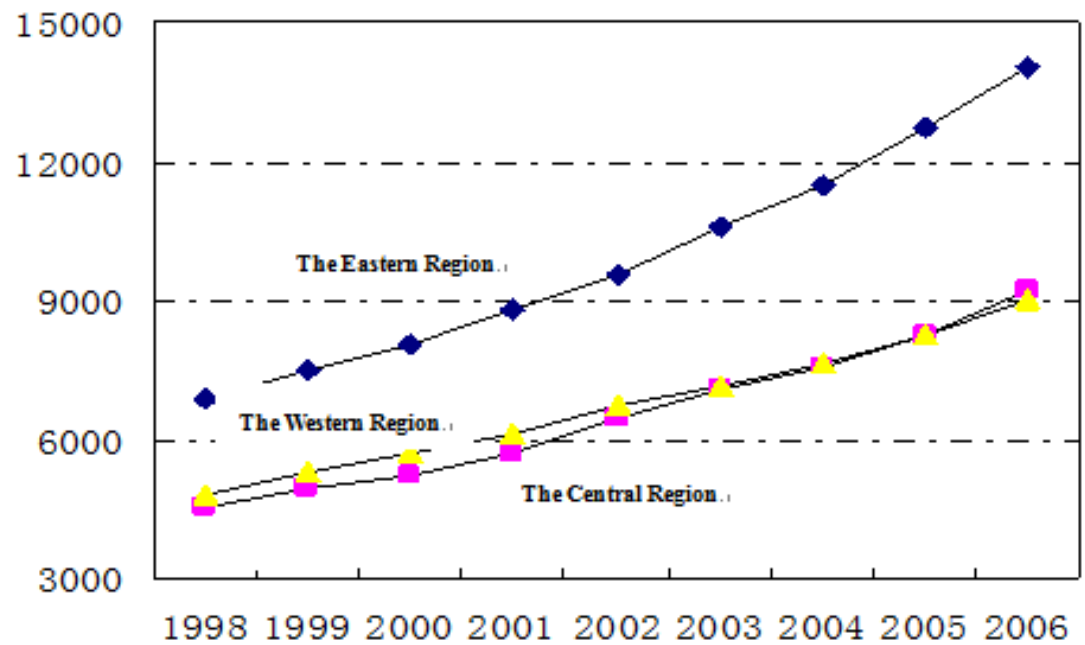

Figure 2: Changes in the income in the central, eastern and western regions

For the regional division of the average housing price in China, Figure 2 compares the changes in the income in the central, western and eastern regions from 1998 to 2006. It's found that the per capita income in the east is prominently higher than those in the western and central regions and its trend is uniformly on the rise. 


\section{Relationship between the Regional Income and the Commercial Housing Price}
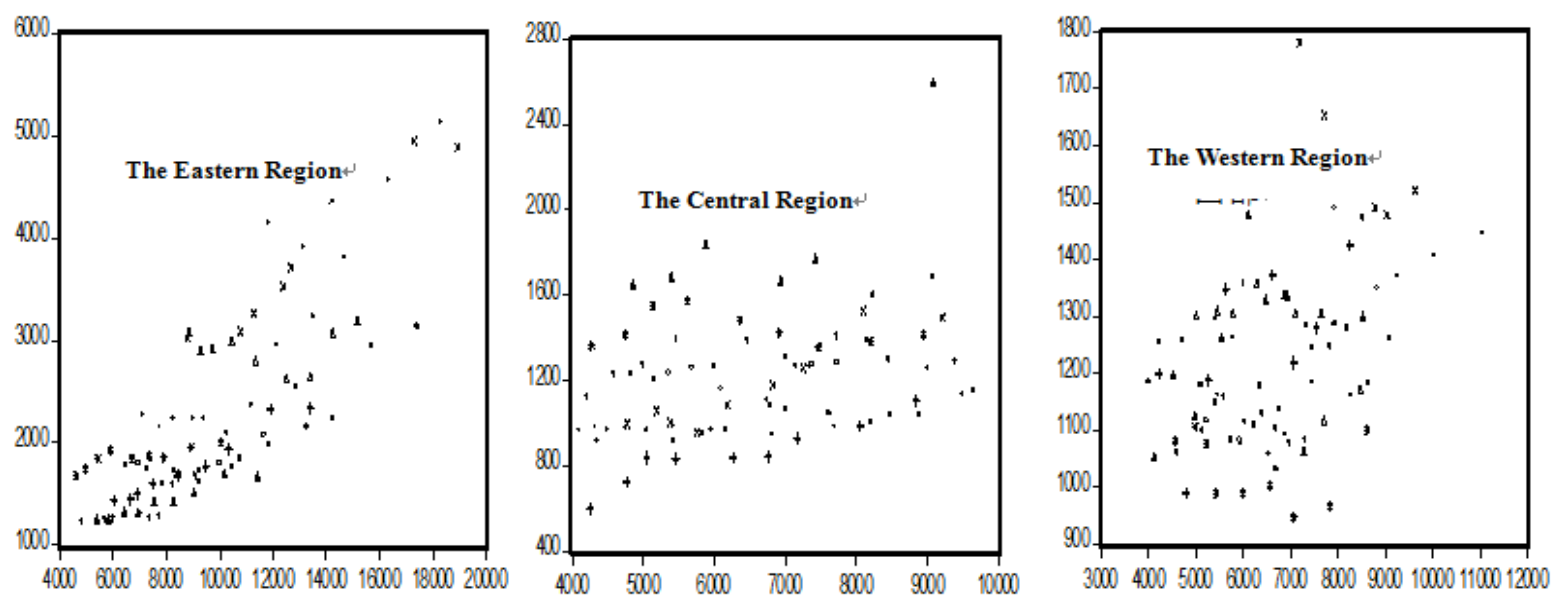

Figure 3: The income and average commercial housing prices in the three types of regions

According to the analysis of Figure 1 and Figure 2, it can be seen that the income change is extremely similar with the housing price change so a further analysis of the relationship between them is conducted in the thesis. In order to observe more clearly, Figure 3 describes the relationship between the average housing price and its corresponding regional income in the eastern, central and western regions of China.

Figure 1 shows that the income is positively correlated with the average housing price. Due to the differences in income levels in different regions, the scatter diagram of Figure 3 has heteroscedasticity, but the positively correlated relationship is relatively obvious. Besides, it can be seen that the values of the correlation coefficient are different between the income and the housing price in the eastern, central and western regions and the values in the eastern and western regions are higher than those in central regions. It also verifies people's intuitive sense of movements in the housing price all the time. Nationally, the growth of the income is the main support to either upward movements or fluctuations of the housing price in both the long term and the short term. In other words, the increase of the housing price is supported by the growth of the income. On the basis of the above descriptive analysis, we can conclude that according to the different stages and different structural features in the development of the commercial housing market in different regions, such multi-pronged policies2 as money and credit, finance and taxation, and land supply should be specially and comprehensively used in the macro-control policy in the commercial housing price by the government to promote the sound and booming development of China's real estate and to continuously improve people's living standards.

\section{References}

[1] Chen Jie, The Income Elastic Estimation of China's Housing Prices and Their Regional Difference, [J] World Economic Papers, Mar. 2010.

[2] Hao Chen. Study on the Correlation of the Value of the Corporate Governance- _ from the two markets of Shanghai and Shenzhen [N] 2009, (3): 40 46 